\title{
A Study of Failure Strength for Fiber-Reinforced Composite Laminates with Consideration of Interface
}

\author{
Junjie Ye, ${ }^{1}$ Yuanying Qiu, ${ }^{1}$ Xuefeng Chen, ${ }^{2}$ Yumin He, ${ }^{3}$ and Zhi Zhai ${ }^{2}$ \\ ${ }^{1}$ Key Laboratory of Ministry of Education for Electronic Equipment Structure Design, Xidian University, Xian 710071, China \\ ${ }^{2}$ State Key Laboratory for Manufacturing Systems Engineering, Xian Jiaotong University, Xian 710049, China \\ ${ }^{3}$ College of Mechanical and Electrical Engineering, Xian University of Architecture and Technology, Xian 710055, China
}

Correspondence should be addressed to Junjie Ye; ronkey6000@sina.com

Received 1 December 2014; Revised 9 March 2015; Accepted 9 March 2015

Academic Editor: Jainagesh A. Sekhar

Copyright (C) 2015 Junjie Ye et al. This is an open access article distributed under the Creative Commons Attribution License, which permits unrestricted use, distribution, and reproduction in any medium, provided the original work is properly cited.

Composite laminates can exhibit the nonlinear properties due to the fiber/matrix interface debonding and matrix plastic deformation. In this paper, by incorporating the interface stress-displacement relations between fibers and matrix, as well as the viscoplastic constitutive model for describing plastic behaviors of matrix materials, a micromechanical model is used to investigate the failure strength of the composites with imperfect interface bonding. Meanwhile, the classic laminate theory, which provides the relation between micro- and macroscale responses for composite laminates, is employed. Theory results show good consistency with the experimental data under unidirectional tensile conditions at both $23^{\circ} \mathrm{C}$ and $650^{\circ} \mathrm{C}$. On this basis, the interface debonding influences on the failure strength of the $[0 / 90]_{s}$ and $[0 / \pm 45 / 90]_{s}$ composite laminates are studied. The numerical results show that all of the unidirectional (UD) laminates with imperfect interface bonding provide a sharp decrease in failure strength in the $\sigma_{x x}-\sigma_{y y}$ plane at $23^{\circ} \mathrm{C}$. However, the decreasing is restricted in some specific region. In addition, for $[0 / 90]_{s}$ and $[0 / \pm 45 / 90]_{s}$ composite laminates, the debonding interface influences on the failure envelope can be ignored when the working temperature is increased to $650^{\circ} \mathrm{C}$.

\section{Introduction}

For improving material properties and satisfying special functional requirements, composites become one of the most important materials nowadays and are widely used in aerospace, energy sources, and so forth [1-4]. Due to their unique constructions and special designs, composites show obvious macroscopic and microscopic characteristics. In other words, the failures of composite structures are related to macroscopic and microscopic stress field. Therefore, it is important for researchers to investigate the microscopic structure feature influence on the macroscopic mechanical properties of composites. At present, both analytical method and finite element method are used to predict the nonlinear stress-strain responses of metal-matrix and polymer-matrix composites. However, most of the traditional analytical methods always rely on various experience parameters. It is difficult for the method to calculate microscopic stressstrain field with a high accuracy. For the finite element method, poor calculation efficiency, difficult modifying for the structure model, results in a poor application in studying microstructure variation effects on the macroscopic mechanical responses.

Due to its flexible structural framework and high calculation efficiency, the generalized method of cells (GMC) based on the uniform axial deformation constraint condition and interface displacement continuous conditions, which was proposed by Aboudi, has been widely used in studying elastoplastic [5-7] and failure problems [8]. Coupled with the GMC and classical lamination theory, the failure envelopes of the polymer-matrix composites were studied by Tang and Zhang [8]. For failure envelopes of $\left[90^{\circ} / 30^{\circ} /-30^{\circ}\right]_{2 s}$ and $\left[90^{\circ} / \pm 45^{\circ} / 0^{\circ}\right]_{2 s}$ laminates, it can be concluded that all matrix failure criteria produce similar results. Based on the GMC and laminate analogy approach, Sun et al. [9] predicted the elastic properties of short sisal fiber reinforced polypropylene composites. The results show that the fiber volume fraction has very small effects on the transverse Young's modulus, 
axial shear modulus, and axial Poisson's ratio. It is no doubt that the micromechanical problems can be easily solved by using GMC model. However, uncoupled subcell normal stress and shear stress lead to the poor calculation accuracy for GMC model. By employing the higher-order displacement expansion, the high-fidelity generalized method of cells (HFGMC) was proposed for solving microscopic stressstrain field with a higher accuracy $[10,11]$. By using the HFGMC theory, Aboudi and Ryvkin [11] studied the progressive damage effects on the behavior of elastic composites. HajAli and Aboudi [12] proposed a new parametric formulation for the HFGMC theory. The numerical results of spatial stress fields for circular and elliptical fibers show good consistency with analytical and numerical solutions.

In the preparation of composite materials, the interface phases between inclusions and matrix will be produced. As a kind of connecting bridge, the interphase plays a critical role in the mechanical properties of composites [13, 14]. At present, some representative interface theories, such as chemical bond theory, transition layer theory, and weak boundary layer theory, are used to describe the interface influences on the mechanical responses of composites $[15,16]$. Similarly, the interface debonding model, which is one of the weak boundary layer theories, has been implemented into the GMC or HFGMC theory for investigating interface failure problem. Once a critical debonding stress has been exceeded, the displacement discontinuity between fibers and matrix is considered. On this basis, Arnold et al. [17] studied the tensile response of composites with imperfect interfacial bonding. By implementing into the evolving compliant interface (ECI) model, Chen et al. [18] developed the GMC to predict the mechanical behaviors of unidirectional metal matrix composites with imperfect interface bonding. The results showed that the theoretical prediction exhibits good agreement with experimental results only when both imperfect interface bonding between fibers and matrix and thermal residual stresses in subcells are taken into consideration. Via fiber of appropriate constitutive relation for fiber/matrix debonding, both the GMC and HFGMC have been applied by Bednarcyk et al. [19] to investigate the transverse deformations of the fiber-reinforced composites. The results indicated that the HFGMC shows a higher accuracy than the GMC for perfecting the transverse response of composites with imperfect interface bonding. However, in spite of HFGMC effectiveness in the mechanical responses and other applications, it has not been applied for composite laminates with imperfect interface bonding. Considering its ability in investigating nonlinear failure problems, the HFGMC is used to study the interface debonding influence on composite laminates by combining with the classical laminate theory.

\section{Modeling Framework of Fiber-Reinforced Composites with Imperfect Interface Bonding}

By establishing the quantitative relation between microscopic constituent properties and macroscopic material properties, the micromechanical methods can be effectively used to investigate the failure mechanisms and mechanical properties of composites. For calculating microscopic stress components with a higher solution precision, the HFGMC was proposed by introducing a higher order displacement component in subcells. For the fiber-reinforced composite laminates as shown in Figure 1(a), a proper unit (Figure 1(b)) is selected and the unit is defined as a representative volume element (RVE). The local constitutive relation between the subcell stress components $\boldsymbol{\sigma}^{(\beta \gamma)}$ and the subcell elastic stiffness matrix $\mathbf{C}^{(\beta \gamma)}$ can be written as follows:

$$
\boldsymbol{\sigma}^{(\beta \gamma)}=\mathbf{C}^{(\beta \gamma)}\left(\boldsymbol{\varepsilon}^{(\beta \gamma)}-\boldsymbol{\varepsilon}^{T(\beta \gamma)}\right)
$$

where the superscripts $\beta$ and $\gamma$ indicate the corresponding subcells. The strain components $\boldsymbol{\varepsilon}^{T(\beta \gamma)}$ indicate the subcell thermal strains. The strain components $\boldsymbol{\varepsilon}^{(\beta \gamma)}$ are subcell strains. It should be noted that the subcell strain components $\boldsymbol{\varepsilon}^{(\beta \gamma)}$ contain the elastic and inelastic strain components. Moreover, the inelastic strain component can be described by using the unified constitutive theory.

For the continuous fiber-reinforced composites, the subcell displacement field function $\tilde{u}_{i}^{(\beta, \gamma)}$ with higher order components in the HFGMC, as well as the subcell average stress variations $S_{i j(m n)}^{(\beta \gamma)}$, can be written as follows $[19,20]$ :

$$
\begin{aligned}
\widetilde{u}_{i}^{(\beta, \gamma)}= & \bar{\varepsilon}_{i j} x_{j}+W_{i(00)}^{(\beta, \gamma)}+y_{2}^{(\beta)} W_{i(10)}^{(\beta, \gamma)}+y_{3}^{(\gamma)} W_{i(01)}^{(\beta, \gamma)} \\
& +\frac{1}{2}\left(3 y_{2}^{(\beta) 2}-\frac{h_{\beta}^{2}}{4}\right) W_{i(20)}^{(\beta, \gamma)}+\frac{1}{2}\left(3 y_{3}^{(\gamma) 2}-\frac{l_{\gamma}^{2}}{4}\right) W_{i(02)}^{(\beta, \gamma)} \\
& (i=1,2,3),
\end{aligned}
$$

$$
\begin{array}{r}
S_{i j(m n)}^{(\beta \gamma)}=\frac{1}{h_{\beta} l_{\gamma}} \int_{-h_{\beta} / 2}^{h_{\beta} / 2} \int_{-l_{\gamma} / 2}^{l_{\gamma} / 2} \sigma_{i j}^{(\beta \gamma)}\left(\bar{y}_{2}^{(\beta)}\right)\left(\bar{y}_{3}^{(\gamma)}\right) d \bar{y}_{2}^{(\beta)} d \bar{y}_{3}^{(\gamma)} \\
(i, j=1,2,3),
\end{array}
$$

where the parameters $h_{\beta}$ and $l_{\gamma}$ are the subcell height and length, respectively. The strain components $\bar{\varepsilon}_{i j}$ indicate the average macroscopic strain. The displacement components $W_{i(00)}^{(\beta, \gamma)}$ and $W_{i(m n)}^{(\beta, \gamma)}$ denote the subcell average displacement and high order average displacement components, respectively. The parameters $\bar{y}_{2}^{(\beta)}$ and $\bar{y}_{3}^{(\gamma)}$ are the local coordinate system in the subcell as shown in Figure 1(b).

The displace field function of composites with perfect interfacial bonding can be acquired by employing (1)-(3). According to the displace and stress boundary conditions in the local coordinate system, combining with the subcell displacement field function $\widetilde{u}_{i}^{(\beta, \gamma)}$, the subcell average stress 


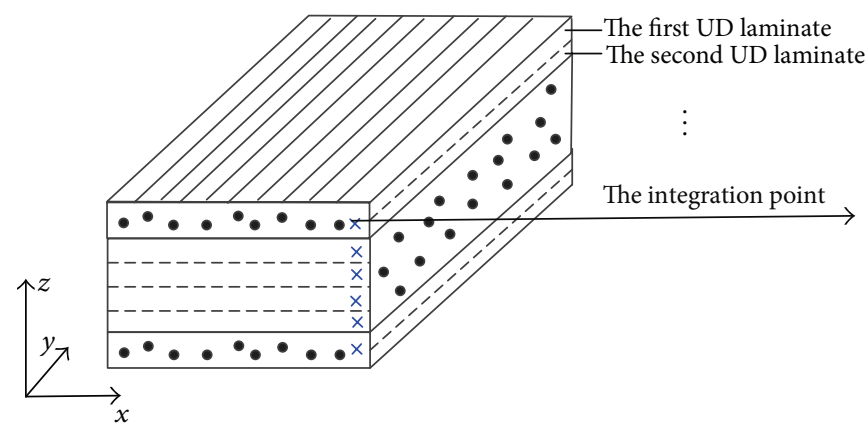

(a)

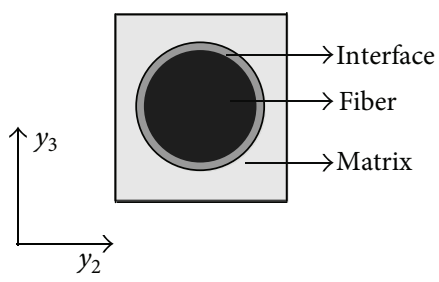

(b)

Figure 1: Composite laminate theory analysis with micromechanical model embedded to the proper unit. (a) Composite laminate theory and (b) a proper unit with interface (RVE).

variations $S_{i j(m n)}^{(\beta \gamma)}$ in the 2 and 3 directions can be acquired as follows:

$$
\begin{gathered}
S_{2 i(00)}^{(1 \gamma)}-\frac{6}{h_{1}} S_{2 i(10)}^{(1 \gamma)}=S_{2 i(00)}^{\left(N_{\beta} \gamma\right)}-\frac{6}{h_{N_{\beta}}} S_{2 i(10)}^{\left(N_{\beta} \gamma\right)} \quad\left(\gamma=1, \ldots, N_{\gamma}\right), \\
S_{3 i(00)}^{(\beta 1)}-\frac{6}{l_{1}} S_{3 i(01)}^{(\beta 1)}=S_{3 i(00)}^{\left(\beta N_{\gamma}\right)}-\frac{6}{l_{N_{\gamma}}} S_{3 i(01)}^{\left(\beta N_{\gamma}\right)} \quad\left(\beta=1, \ldots, N_{\beta}\right) \\
S_{2 i(00)}^{(\beta \gamma)}+\frac{6}{h_{\beta}} S_{2 i(10)}^{(\beta \gamma)}=S_{2 i(00)}^{(\beta+1 \gamma)}-\frac{6}{h_{\beta+1}} S_{2 i(10)}^{(\beta+1 \gamma)} \\
\left(\beta=1, \ldots, N_{\beta}-1 ; \gamma=1, \ldots, N_{\gamma}\right) \\
S_{3 i(00)}^{(\beta \gamma)}+\frac{6}{l_{\gamma}} S_{2 i(01)}^{(\beta \gamma)}=S_{3 i(00)}^{(\beta \gamma+1)}-\frac{6}{l_{\gamma+1}} S_{3 i(01)}^{(\beta \gamma+1)} \\
\left(\beta=1, \ldots, N_{\beta} ; \gamma=1, \ldots, N_{\gamma}-1\right) .
\end{gathered}
$$

By using the equilibrium equations and the surface stress components per unit area, the subcell average stress variation relations between $S_{2 i(10)}^{(\beta \gamma)}$ and $S_{3 i(01)}^{(\beta \gamma)}$ can be expressed as follows:

$$
\frac{1}{h_{\beta}^{2}} S_{2 i(10)}^{(\beta \gamma)}+\frac{1}{l_{r}^{2}} S_{3 i(01)}^{(\beta \gamma)}=0
$$

According to [19], with consideration of the interfacial bonding influences on continuous fiber-reinforced composites, the stress relation between the neighboring subcells along with 2 directions can be written as

$$
u_{i}^{(\beta \gamma)}\left(y_{2}^{(\beta)}=\frac{h_{\beta}}{2}\right)-u_{i}^{(\beta+1 \gamma)}\left(y_{2}^{(\beta)}=-\frac{h_{\beta+1}}{2}\right)=-\left[u_{2 i}\right]^{I},
$$

where the superscript $I$ indicates the interphase between the neighboring subcells. The parameter $u_{2 i}$ indicates the interface displacement components along with 2 directions.
Similarly, the stress relation between the neighboring subcells along with 3 directions for composites with the interfacial debonding can be written as

$$
u_{i}^{(\beta \gamma)}\left(y_{3}^{(\gamma)}=\frac{l_{\gamma}}{2}\right)-u_{i}^{(\beta \gamma+1)}\left(y_{3}^{(\beta)}=-\frac{l_{\gamma+1}}{2}\right)=-\left[u_{3 i}\right]^{I} .
$$

The parameter $\left[u_{3 i}\right]^{I}$ is interface displacement components along with 3 directions.

Here, the interface displacement components can be written as follows [21]:

$$
\left[u_{j i}\right]^{I}=R_{j i}^{(\beta \gamma)} \sigma_{j i}^{I(\beta \gamma)}
$$

where the parameters $R_{j i}^{(\beta \gamma)}$ and $\sigma_{j i}^{I(\beta \gamma)}$ indicate the interface displacement debonding coefficients and the interface stress components between fiber and matrix, respectively. It should be noted that the variations $R_{j i}^{(\beta \gamma)}$ and $\sigma_{j i}^{I(\beta \gamma)}$ are both timedependent variations.

By combining (2) with (3), the average sense results in (7)(8) can be written as

$$
\begin{aligned}
W_{i(00)}^{(\beta \gamma)}+ & \frac{h_{\beta}}{2} W_{i(10)}^{(\beta \gamma)}+\frac{h_{\beta}^{2}}{4} W_{i(20)}^{(\beta \gamma)} \\
& -\left(W_{i(00)}^{(\beta+1 \gamma)}-\frac{h_{\beta+1}}{2} W_{i(10)}^{(\beta+1 \gamma)}+\frac{h_{\beta+1}^{2}}{4} W_{i(20)}^{(\beta+1 \gamma)}\right) \\
= & -R_{2 i}^{(\beta \gamma)}\left(S_{2 i(00)}^{(\beta \gamma)}+\frac{6}{h_{\beta}} S_{2 i(10)}^{(\beta \gamma)}\right), \\
W_{i(00)}^{(\beta \gamma)}+ & \frac{l_{\gamma}}{2} W_{i(01)}^{(\beta \gamma)}+\frac{l^{2}}{4} W_{i(02)}^{(\beta \gamma)} \\
& -\left(W_{i(00)}^{(\beta \gamma+1)}-\frac{l_{\gamma+1}}{2} W_{i(01)}^{(\beta \gamma+1)}+\frac{l_{\gamma+1}^{2}}{4} W_{i(02)}^{(\beta \gamma+1)}\right) \\
= & -R_{3 i}^{(\beta \gamma)}\left(S_{3 i(00)}^{(\beta \gamma)}+\frac{6}{l_{\gamma}} S_{3 i(01)}^{(\beta \gamma)}\right) .
\end{aligned}
$$


By combining (4)-(5) with (9), the subcell average stress components $S_{i j(m n)}^{(\beta \gamma)}$ can be calculated. Furthermore, the nonlinear stress-strain behaviors of composites with imperfect interface bonding can be acquired through implementing subcell average stress components into (1). According to the homogenization theory, the macroscopic stress components $\sigma$ of the composite can be obtained as follows:

$$
\boldsymbol{\sigma}=\frac{1}{h l} \sum_{\beta=1}^{N_{\beta}} \sum_{\gamma=1}^{N_{\gamma}} h_{\beta} l_{\gamma} \mathbf{C}^{(\beta \gamma)}\left(\boldsymbol{\varepsilon}^{(\beta \gamma)}-\boldsymbol{\varepsilon}^{T(\beta \gamma)}\right) .
$$

The thermal residual stress is defined as the mismatch stress between fibers and matrix due to the temperature variation from the manufacturing temperature to the room temperature. According to the orthogonalization characteristics of Legendre polynomial in [20], the subcell strain components $\boldsymbol{\varepsilon}^{(\beta \gamma)}$ can be expressed with the macroscopic average strain components. It should be noted that there is no mechanical loading applied during cooling. In other words, the macroscopic stress components $\sigma$ should be equal to zero. From (10), it can be found the thermal residual stress components in the RVE can be acquired once the macroscopic average strain components are confirmed.

\section{Unidirectional Tensile Response of Composite Laminates}

3.1. The Relation between Internal Force and Strain of Composite Laminates. In the design process of composite products, a unidirectional (UD) laminate is always economically unreasonable due to its especial engineering requirements or complex load environments. Typical composite structures in engineering field are multidirectional layer composite materials, such as composite laminates. According to their designable and strength requirement, the composite laminates can be manufactured by a series of unidirectional laminates with different layer orientations. Furthermore, the mechanical properties can be further improved by using optimization algorithm. The stress-stain relation of composite laminates can be written as follows [22]:

$$
\left[\begin{array}{c}
\mathbf{N} \\
\cdots \\
\mathbf{M}
\end{array}\right]=\left[\begin{array}{ccc}
\mathbf{A} & \vdots & \mathbf{B} \\
\cdots & \\
\mathbf{B} & & \\
\mathbf{D}
\end{array}\right]\left[\begin{array}{c}
\boldsymbol{\varepsilon} \\
\cdots \\
\mathbf{k}
\end{array}\right],
$$

where $\mathbf{A}$ and $\mathbf{D}$ are the in-plane stiffenss matrix and bending stiffness matrix, respectively. The matrix $\mathbf{B}$ is the coupling stiffness matrix, which refers to the in-plane strain and internal bending force. The vectors $\mathbf{N}$ and $\mathbf{M}$ indicate the internal force components and internal moment components, respectively. The vectors $\boldsymbol{\varepsilon}$ and $\mathbf{k}$ are referred to as strain components.

3.2. Model Validation. In this study, the composites system include SCS-6 fiber and titanium matrix alloy (Timetal 21S) matrix. The fiber volume fraction is $33 \%$. The fiber and matrix are assumed to be strain free at $850^{\circ} \mathrm{C}$. The thermal residual stresses in the RVE are generated when the manufacturing temperature cools down to room temperature at $20^{\circ} \mathrm{C}$. The fibers are assumed to be of linear elasticity until they reach to the ultimate strength. While the Timetal $21 \mathrm{~S}$ matrix, which is described by a generalized viscoplasticity with potential structure (GVIPS), is considered to be elastoplastic material, the relationship between the inelastic strain rate $\dot{\varepsilon}_{i j}^{I}$ and the deviatoric stress components $s_{i j}$ in the GVIPS can be written as follows [23]:

$$
\begin{gathered}
\dot{\varepsilon}_{i j}^{I}=\frac{3}{2} \frac{\mu F^{n}}{\kappa} \frac{s_{i j}}{\sqrt{(3 / 2)\left(s_{i j}-\Lambda_{i j}\right)\left(s_{i j}-\Lambda_{i j}\right)}}, \\
F=\left\langle\frac{\sqrt{J_{2}}}{\kappa}-\left\langle 1-\frac{\beta}{\kappa_{0}} \sqrt{\frac{3}{2} \Lambda_{i j} \Lambda_{i j}}\right\rangle\right\rangle .
\end{gathered}
$$

The differential equation of the components $\Lambda_{i j}$ with respect to time can be expressed as follows:

$$
\begin{aligned}
\dot{\Lambda}_{i j}= & \frac{\kappa_{0}^{2}}{3 B_{0}\left(1+B_{1} p G^{p-1}\right)} \\
& \cdot\left(\delta_{i k} \delta_{j l}-\frac{3 B_{1} p(p-1) G^{p-2}}{\kappa_{0}^{2}\left(1+p B_{1} G^{p-1}(6 p-5)\right)} A_{i j} A_{k l}\right) \dot{A}_{k l}, \\
\dot{A}_{k l}= & \dot{\varepsilon}_{k l}-\Lambda_{k l}\left(\frac{3 \beta \kappa}{2 \kappa_{0}^{2}} \sqrt{\frac{2}{3} \dot{\varepsilon}_{k l} \dot{\varepsilon}_{k l}} \frac{H_{\nu}[Y]}{\sqrt{G}}-\frac{3}{\kappa_{0}^{2}} R_{\alpha} \beta_{o} G^{q}\right),
\end{aligned}
$$

where the material parameters $\kappa, \beta, B_{o}, R_{\alpha}, n, p, q, B_{1}$ are acquired by experimental method.

The material parameters of SCS-6/Timetal 21S are shown in Table 1. From Table 1, it can be easily found that the failure strength of the fiber and matrix are both temperaturedependent variations. To offer evidence for the predictive capabilities of the modeling framework, the macroscopic stress-strain responses of cross-ply symmetric laminates $\left([0 / 90]_{s}\right)$ are displayed as shown in Figure 2. In Figure 2, the thermal residual stresses in subcells and the thermal variation are both considered. However, the failure problems in subcells are not considered. For comparisons, the experimental data acquired by Cervay [24] are also shown in the corresponding figures. Obviously, the theoretical predictions and experimental data at both $23^{\circ} \mathrm{C}$ and $650^{\circ} \mathrm{C}$ offer a certain evidence for the feasibility of using the modeling framework to analyze the failure strength of the composite laminates. In addition, by comparing Figure 2(a) with Figure 2(b), it can be easily found that the stress-strain curves of composites are temperature dependent for composite laminates due to their property differences in constituent materials at different working temperatures.

\section{Failure Envelope Investigation of Composite Laminates}

According to the actual engineering demanding, the mechanical properties of composite structures can be improved 
TABLE 1: Material constant and viscoplastic parameters of Timetal 21S matrix.

\begin{tabular}{|c|c|c|c|c|c|}
\hline \multirow{2}{*}{$\begin{array}{l}\text { Material } \\
T\left({ }^{\circ} \mathrm{C}\right)\end{array}$} & \multicolumn{3}{|c|}{ Timetal 21S matrix } & \multicolumn{2}{|c|}{ SCS-6 fiber } \\
\hline & 23 & 300 & 650 & 21 & 650 \\
\hline Elastic modulus E/Gpa & 114.1 & 107.9 & 80.7 & 393 & 59.7 \\
\hline Thermal expansion coefficient $\left(10^{-6}\right)$ & 7.72 & 9.21 & 12.13 & 3.564 & 3.826 \\
\hline Poisson's ration & 0.365 & 0.365 & 0.365 & 0.25 & 0.25 \\
\hline$\kappa(\mathrm{Mpa})$ & 1029 & 768.4 & 5.861 & - & - \\
\hline$\beta$ & 0.001 & 0 & 0 & - & - \\
\hline$B_{0}(\mathrm{~Pa})$ & 69.08 & 103.5 & 587.0 & - & - \\
\hline$R_{\alpha}(1 / \mathrm{sec})$ & 0 & 0 & $1.0 * 10^{-6}$ & - & - \\
\hline Failure strength (Mpa) & 1190 & - & 460 & 2584 & 2380 \\
\hline \multicolumn{6}{|c|}{$n=3.3, B_{1}=0.05, p=1.8, q=1.35$} \\
\hline
\end{tabular}

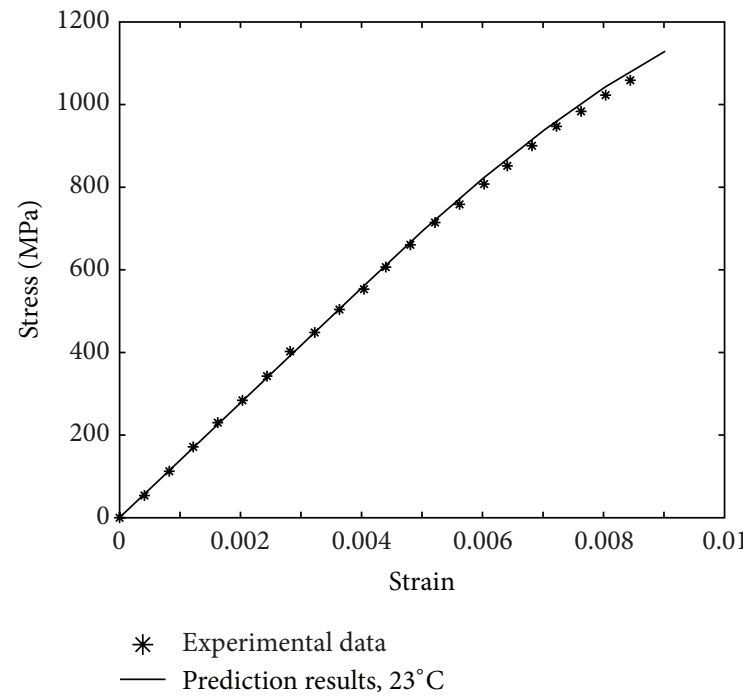

(a)

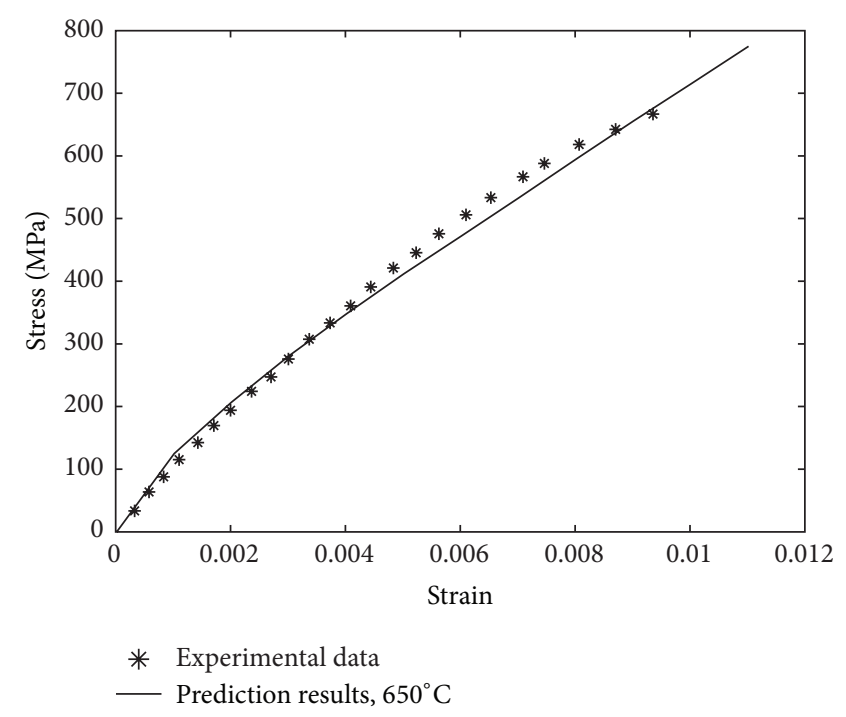

(b)

FIgURE 2: The predicted and experimental tensile stress-strain responses of $[0 / 90]_{s}$ laminate: (a) $23^{\circ} \mathrm{C}$ and (b) $650^{\circ} \mathrm{C}$.

through optimizing stacking sequences. However, due to the long experimental period and high cost, the experimental method can hardly be used to acquire the failure strength of composite laminates. Here, the failure envelopes of $[0 / 90]_{s}$ and $[0 / \pm 45 / 90]_{s}$ composite laminates with imperfect interface bonding are studied. The material parameters of SCS6/Timetal $21 \mathrm{~S}$ can be seen in Table 1 .

In the composite laminates, the microscopic stress and strain fields for each of the UD laminate can be acquired by using the HFGMC theory at the integration point along thickness direction as shown in Figure 1(a). Once the microscopic stress or strain distributions are acquired, the Tsai-Hill failure criterion can be employed to investigate the failure strength of composite laminates. Here, the subcell stiffness is zero when the subcell stress reaches to the failure strength. In addition, it should be noted that the failure strength of composite laminates is defined as the complete failure for all subcells in the RVE along with the thickness direction as shown in Figure 1(a).
4.1. The Failure Envelope Predictions of $[0 / 90]_{s}$ Composite Laminates. There is no doubt that the failure strength of composites is closely related to the interfacial properties between fibers and matrix. For the composite laminates, a different arrangement of the UD laminate (as shown in Figure 1(a)) with imperfect interface bonding between fibers and matrix may lead to the variation of failure strength. In order to investigate the most unfavorable conditions, all of the UD laminates with imperfect interface bonding are investigated. Working temperatures, namely, $23^{\circ} \mathrm{C}$ and $650^{\circ} \mathrm{C}$, are both considered in the examples. The numerical results are also shown in Figures 3 and 4, respectively.

For the $[0 / 90]_{s}$ composite laminates with perfect interface bonding, the failure envelopes that intersect the horizontal and vertical axes of Figures 3 and 4 are defined as A, B, C, and D. Similarly, the failure envelopes that intersect the horizontal and vertical axes of Figures 3 and 4 are defined as $A_{1}, B_{1}, C_{1}$, and $D_{1}$ for the $[0 / 90]_{s}$ composite laminates with imperfect interface bonding. The failure stresses that 
TABLE 2: The failure stresses of the $[0 / 90]_{s}$ composite laminates (Mpa).

\begin{tabular}{lccccccccccc}
\hline \multicolumn{2}{c}{$23^{\circ} \mathrm{C}$, no-debonding interface } & \multicolumn{2}{c}{$23^{\circ} \mathrm{C}$, debonding interface } & \multicolumn{2}{c}{$650^{\circ} \mathrm{C}$, no-debonding interface } & \multicolumn{3}{c}{$650^{\circ} \mathrm{C}$, debonding interface } \\
Points & $x x-y y$ & $x x-x y$ & Points & $x x-y y$ & $x x-x y$ & Points & $x x-y y$ & $x x-x y$ & Points & $x x-y y$ & $x x-x y$ \\
\hline A & 1496.1 & 1496.1 & $\mathrm{~A}_{1}$ & 1157.6 & 1157.6 & $\mathrm{~A}$ & 663.2 & 663.2 & $\mathrm{~A}_{1}$ & 621.2 & 621.2 \\
$\mathrm{~B}$ & 1565.1 & 873.6 & $\mathrm{~B}_{1}$ & 1173.4 & 574.3 & $\mathrm{~B}$ & 663.3 & 283.2 & $\mathrm{~B}_{1}$ & 619.8 & 255.6 \\
$\mathrm{C}$ & -1605.1 & -1605.1 & $\mathrm{C}_{1}$ & -1605.1 & -1605.1 & $\mathrm{C}$ & -677.7 & -677.7 & $\mathrm{C}_{1}$ & -677.7 & -677.7 \\
$\mathrm{D}$ & -1544.4 & -873.5 & $\mathrm{D}_{1}-1544.4$ & -567.4 & $\mathrm{D}$ & -669.4 & -283.2 & $\mathrm{D}_{1}$ & -669.4 & -253.5 \\
\hline
\end{tabular}

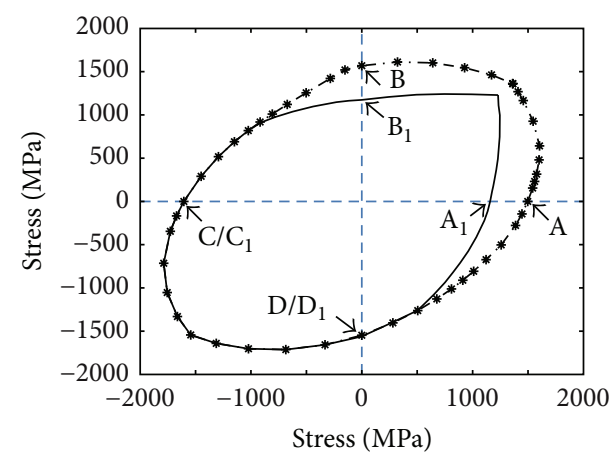

_ Imperfect interface bonding

.* - Perfect interface bonding

(a)

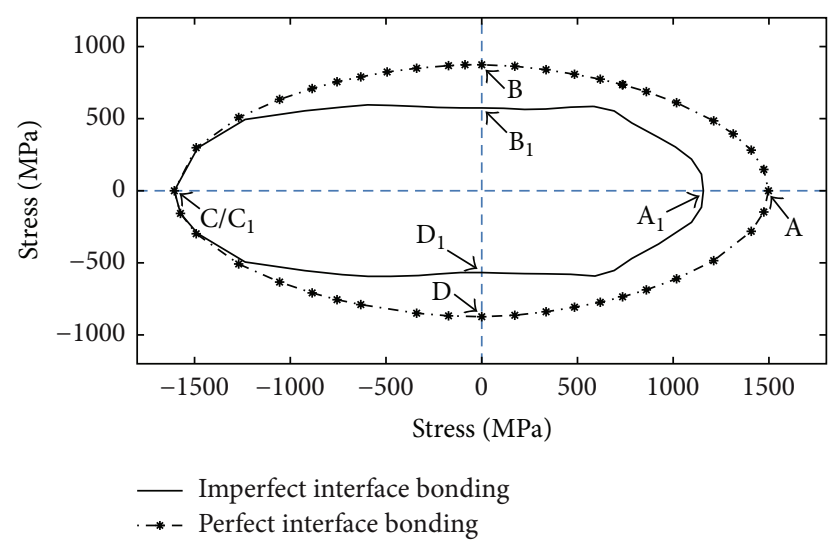

(b)

FIGURE 3: The failure envelopes of $[0 / / 90]_{s}$ laminate at $23^{\circ} \mathrm{C}$ : (a) $x x-y y$ and (b) $x x-x y$.

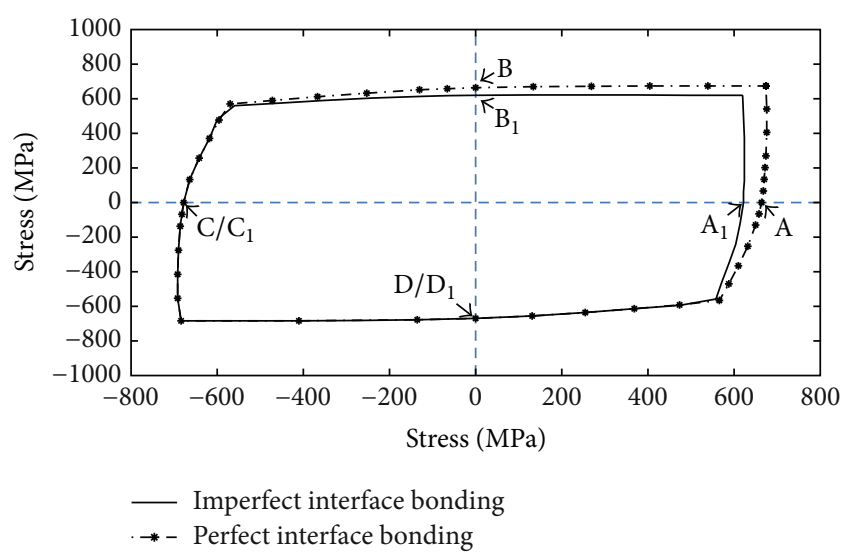

(a)

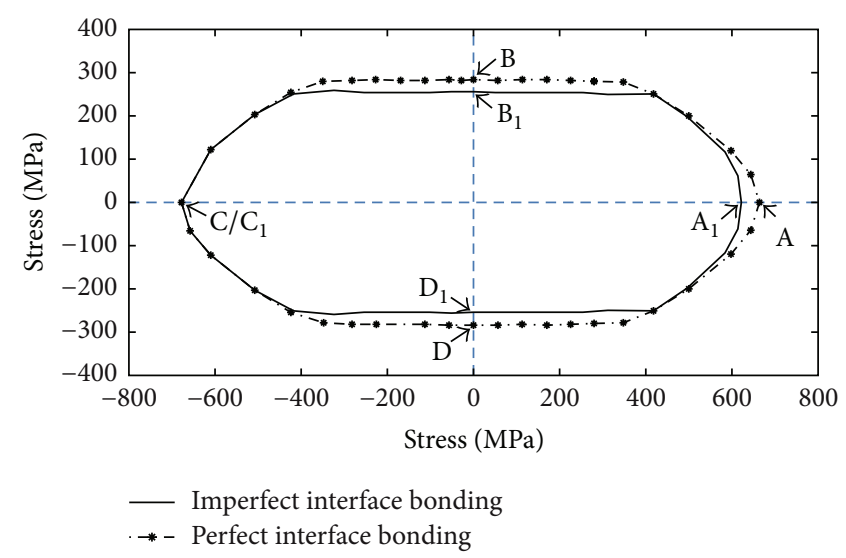

(b)

FIgURE 4: The failure envelopes of $[0 / / 90]_{s}$ laminate at $650^{\circ} \mathrm{C}$ : (a) $x x-y y$ and (b) $x x-x y$.

correspond to the horizontal and vertical axes of Figures 3 and 4 can be found in Table 2. In a word, compared with no debonding interfaces of composite laminates, all of the UD laminates with debonding interfaces show distinct decreasing in failure strength. Meanwhile, the failure strength of SCS6/Timetal $21 \mathrm{~S}$ composites is also temperature dependent.

From Figure 3(a), it can be concluded that the failure strength differences between the no-debonding interface and all of the UD laminates with debonding interfaces can only be found in the first, second, and fourth quadrants. However, for compression-compression loading in the third quadrant, the decrease of failure strength can hardly be found in the $\sigma_{x x}-\sigma_{y y}$ stress plane. Moreover, the maximum differences are presented in the $x$ - and $y$-directional tensile loadings. For the $x$ - and $y$-directional tensile loadings, the no-debonding interface provides a $29 \%$ and $33.5 \%$ increase relative to that of all of the UD laminates with debonding interfaces, respectively. Figure 3(b) shows the failure envelopes in the $\sigma_{x x}-\sigma_{x y}$ stress plane. Comparing Figure 3(a) with Figure 3(b), the failure envelope shape shows distinct difference. Moreover, the pure shear loading provides the maximum difference for failure strength between no debonding interfaces and all of the UD laminates with debonding interfaces in the $\sigma_{x x}-\sigma_{x y}$ stress plane. 


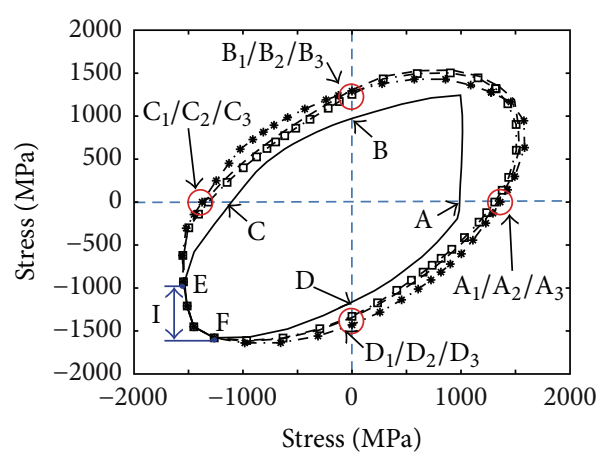

— All layers, debonding
$-\rightarrow-$ First layer, debonding
$-\square-$ Second layer, debonding
--- Third layer, debonding

(a)

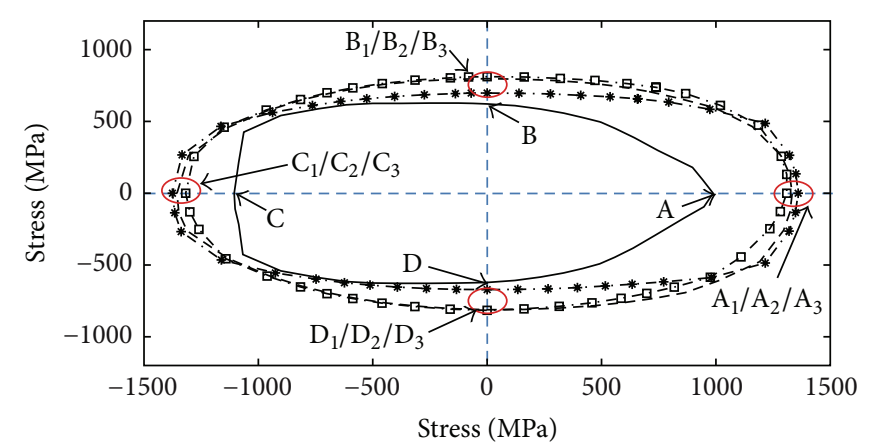

_ All layers, debonding

* - First layer, debonding

$\rightarrow-$ - Second layer, debonding

- - - Third layer, debonding

(b)

Figure 5: The failure envelopes of $[0 / \pm 45 / 90]_{s}$ laminate at $23^{\circ} \mathrm{C}$ : (a) $x x-y y$ and (b) $x x-x y$.

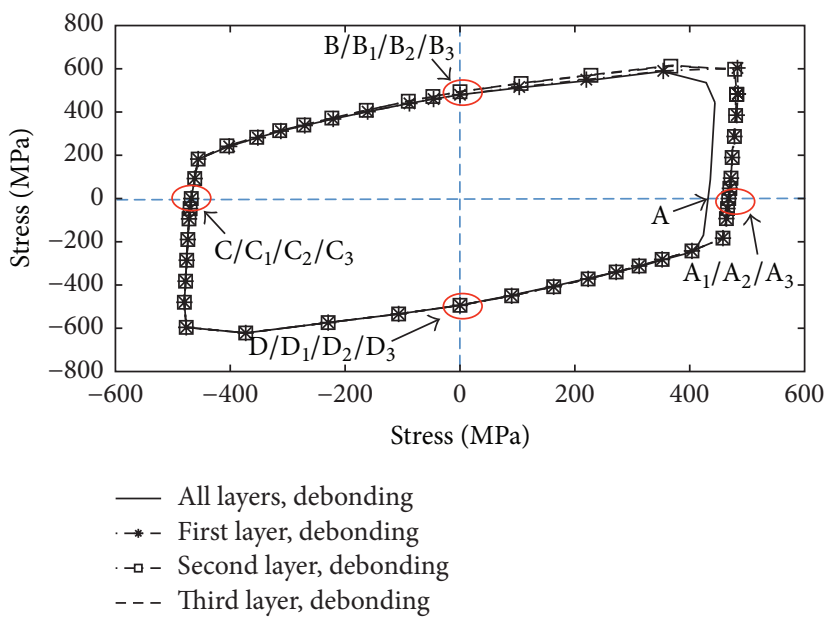

(a)

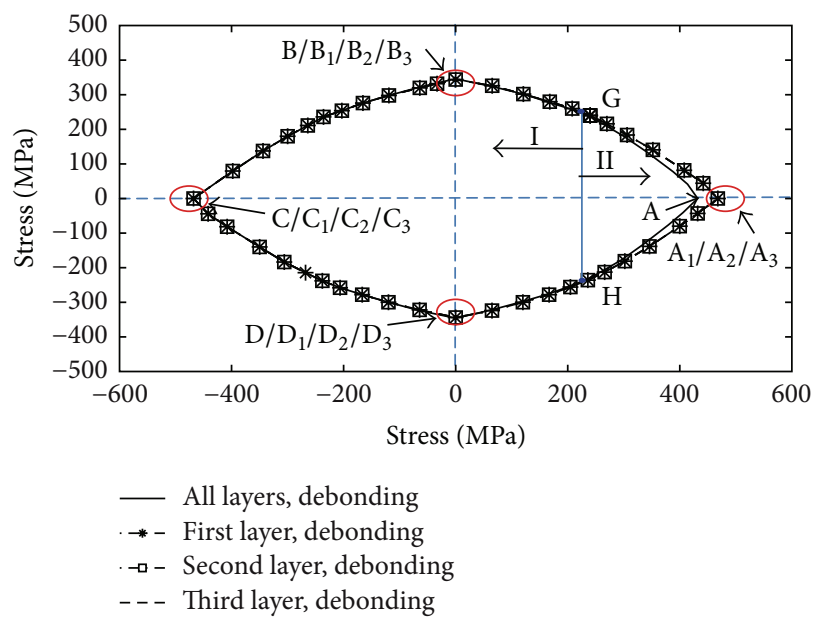

(b)

Figure 6: The failure envelopes of $[0 / \pm 45 / 90]_{s}$ laminate at $650^{\circ} \mathrm{C}$ : (a) $x x-y y$ and (b) $x x-x y$.

Figure 4 shows the failure envelopes of the $[0 / 90]_{s}$ composite laminates when the working temperature is increased to $650^{\circ} \mathrm{C}$. Compared with the failure envelope at $23^{\circ} \mathrm{C}$, it can be clearly seen that the interface debonding influences on failure envelope are relatively small. The relative error of maximum difference value in the $\sigma_{x x}-\sigma_{y y}$ stress plane and $\sigma_{x x}-\sigma_{x y}$ stress plane is less than $10 \%$. That is, the interface debonding influences on the failure strength of $[0 / 90]_{s}$ composite laminates can be ignored in the $\sigma_{x x}-\sigma_{y y}$ and $\sigma_{x x}-\sigma_{x y}$ stress planes when the working temperature is increased to $650^{\circ} \mathrm{C}$.

4.2. The Failure Envelope Predictions of $[0 / \pm 45 / 90]_{s}$ Composite Laminates. As one of the most typical layer structures, the failure analysis of $[0 / \pm 45 / 90]_{s}$ composite laminates is also investigated. For the composite structures with imperfect interface bonding in a specific unidirectional composite laminate, it is hardly for researchers to study the imperfect interface influences on failure envelopes. Therefore, a UD laminate with imperfect interface bonding is designed in different layers. The definition of layer sequence is as shown in Figure 1. Clearly, the top of the layer is defined as the first UD laminate. Due to its symmetrical features, the failure envelopes of the first, second, and third UD laminate with imperfect interface bonding are discussed. For comparisons, all of the UD laminates with debonding interfaces are also discussed as shown in the corresponding figures. Moreover, the working temperature variations influences on the failure strength are also investigated in the $\sigma_{x x}-\sigma_{y y}$ and $\sigma_{x x}-\sigma_{x y}$ stress planes. Figures 5 and 6 show the debonding interface influences on the failure envelopes of composite laminates at $23^{\circ} \mathrm{C}, 650^{\circ} \mathrm{C}$, respectively. For all of the UD laminates with debonding interfaces, the failure envelopes that intersect the horizontal and vertical axes of Figures 5 and 6 are defined as the points $\mathrm{A}, \mathrm{B}, \mathrm{C}$, and $\mathrm{D}$. The corresponding results can be 
TABLE 3: The failure stresses of the $[0 / \pm 45 / 90]_{s}$ composite laminates with imperfect interface bonding at $23^{\circ} \mathrm{C}(\mathrm{Mpa})$.

\begin{tabular}{lccccccccccc}
\hline \multicolumn{2}{c}{ All of the UD laminates } & \multicolumn{3}{c}{ The first UD laminate } & \multicolumn{2}{c}{ The second UD laminate } & \multicolumn{3}{c}{ The third UD laminate } \\
Points & $x x-y y$ & $x x-x y$ & Points & $x x-y y$ & $x x-x y$ & Points & $x x-y y$ & $x x-x y$ & Points & $x x-y y$ & $x x-x y$ \\
\hline A & 986.6 & 986.6 & $\mathrm{~A}_{1}$ & 1358.7 & 1358.7 & $\mathrm{~A}_{2}$ & 1306.5 & 1306.5 & $\mathrm{~A}_{3}$ & 1331.2 & 1331.2 \\
$\mathrm{~B}$ & 972.8 & 620.7 & $\mathrm{~B}_{1}$ & 1290.4 & 697.2 & $\mathrm{~B}_{2}$ & 1252.6 & 810.9 & $\mathrm{~B}_{3}$ & 1304.2 & 797.1 \\
$\mathrm{C}$ & -1104.4 & -1104.4 & $\mathrm{C}_{1}$ & -1374.5 & -1374.5 & $\mathrm{C}_{2}$ & -1316.6 & -1316.6 & $\mathrm{C}_{3}$ & -1354.5 & -1354.5 \\
$\mathrm{D}$ & -1162.4 & -620.7 & $\mathrm{D}_{1}$ & -1428.2 & -671.0 & $\mathrm{D}_{2}$ & -1328.3 & -815.1 & $\mathrm{D}_{3}$ & -1342.1 & -810.9 \\
\hline
\end{tabular}

TABLE 4: The failure stresses of the $[0 / \pm 45 / 90]_{s}$ composite laminates with imperfect interface bonding at $650^{\circ} \mathrm{C}(\mathrm{Mpa})$.

\begin{tabular}{lccccccccccc}
\hline \multicolumn{2}{c}{ All of the UD laminates } & \multicolumn{3}{c}{ The first UD laminate } & \multicolumn{3}{c}{ The second UD laminate } & \multicolumn{3}{c}{ The third UD laminate } \\
Points & $x x-y y$ & $x x-x y$ & Points & $x x-y y$ & $x x-x y$ & Points & $x x-y y$ & $x x-x y$ & Points & $x x-y y$ & $x x-x y$ \\
\hline A & 431.3 & 431.3 & $\mathrm{~A}_{1}$ & 467.1 & 467.1 & $\mathrm{~A}_{2}$ & 467.1 & 467.1 & $\mathrm{~A}_{3}$ & 467.1 \\
B & 479.5 & 343.1 & $\mathrm{~B}_{1}$ & 479.5 & 343.1 & $\mathrm{~B}_{2}$ & 493.3 & 343.1 & $\mathrm{~B}_{3}$ & 467.1 \\
$\mathrm{C}$ & -467.1 & -467.1 & $\mathrm{C}_{1}$ & -467.1 & -467.1 & $\mathrm{C}_{2}$ & -467.1 & -467.1 & $\mathrm{C}_{3}$ & -467.1 & -467.1 \\
$\mathrm{D}$ & -493.3 & -343.1 & $\mathrm{D}_{1}$ & -493.3 & -343.1 & $\mathrm{D}_{2}$ & -493.3 & -343.1 & $\mathrm{D}_{3}$ & -493.3 & -343.1 \\
\hline
\end{tabular}

found in Tables 3 and 4, respectively. The subscripts 1, 2, and 3 in Figures 5 and 6 indicate the first, second, and third UD laminate with imperfect interface bonding.

Figure 5 presents the interface debonding influences on the failure strength of the composite laminates at $23^{\circ} \mathrm{C}$. Table 3 shows the failure stresses that correspond to the horizontal and vertical axes at $23^{\circ} \mathrm{C}$. As can be seen in Figures 5(a)-5(b), the imperfect interface bonding influences on failure envelopes show substantial difference in the $\sigma_{x x}-\sigma_{y y}$ and $\sigma_{x x}-\sigma_{x y}$ stress planes. Some specific UD laminate with imperfect interface bonding provides the higher resistant failure ability than all of the UD laminates with imperfect interface bonding. In addition, the failure envelopes in the four different bonding conditions present small overlap regions between two characteristic points $\mathrm{E}$ and $\mathrm{F}$ in the $\sigma_{x x}-\sigma_{y y}$ stress plane as shown in Figure 5(a). The overlap region is defined as region I. For four different interface bonding conditions, the failure strength in region I shows good consistency. However, compared with some specific UD laminate with imperfect interface bonding, the failure strength tends to decrease sharply when all of the UD laminates with imperfect interface bonding are considered outside the region I. Moreover, the failure envelope differences among different UD laminates with imperfect interface bonding can be clearly distinguished. For the $x$-directional tensile and compressive loadings, as well as the $y$-directional tensile and compressive loadings, it can be seen from Table 3 that the first UD laminate with imperfect interface bonding provides the highest failure strength. From Figure 5(b), it is clearly seen that there is no overlap region in the $\sigma_{x x}-\sigma_{x y}$ stress plane. All of the UD laminates with imperfect interface bonding provide the lowest failure strength. Meanwhile, the second layer UD laminate with imperfect interface bonding provides the highest pure shear failure strength.

Figure 6 shows the imperfect interface bonding influences on failure strength of composite laminates when the working temperature is increased to $650^{\circ} \mathrm{C}$. Table 4 shows the failure stresses that correspond to the horizontal and vertical axes at $650^{\circ} \mathrm{C}$. By comparing Figure 5, the working temperature effects on the failure strength show a great difference. For the $\sigma_{x x}-\sigma_{y y}$ stress loading as shown in Figure 6(a), the failure strength in four different interface bonding conditions shows good consistency in the third quadrant. It means that the interface bonding modes can be ignored in the compressioncompression loading. However, only a little difference can be found in the second quadrant. In the $x$-directional tensile loading, the failure strength tends to be consistency for the first, second, and third UD laminates with imperfect interface bonding as shown in Table 4 . In the $\sigma_{x x}-\sigma_{x y}$ stress plane as shown in Figure 6(b), the failure envelopes present axisymmetric characteristics. And two characteristic points are defined as $G$ and $H$. On the left side of the line C-D is defined as region $\mathrm{I}$, and the other region is defined as region II. For the four different debonding modes, it is hardly to discern the interface debonding influences on failure envelopes of composite laminates in region I. In addition, it should be noted that the imperfect interface bonding influences on failure envelopes can be ignored in the pure shear loading.

\section{Conclusions}

In this paper, a micromechanical model is used to investigate the interface debonding influences on failure envelopes of typical composite structures. The classic laminate theory and the GVIPS viscoplastic model are both introduced for describing the nonlinear behaviors of the composite laminates. In addition, the evolving debonding model is presented to study the interface debonding influences on $[0 / / 90]_{s}$ and $[0 / \pm 45 / 90]_{s}$ composites laminates with imperfect interface bonding. The failure envelopes are both considered at $23^{\circ} \mathrm{C}$ and $650^{\circ} \mathrm{C}$. Based on investigations, the following conclusions can be drawn.

(1) The failure envelopes of SCS-6/Timetal 21S composites are temperature dependent. 
(2) For $[0 / 90]_{s}$ composite laminates in the $\sigma_{x x}-\sigma_{y y}$ stress plane, the failure strength between no-debonding interface and all of the UD laminates with debonding interfaces tend to be consistent in compressioncompression loading when the working temperature is $23^{\circ} \mathrm{C}$. Moreover, the interface debonding influences on failure strength can be ignored in both $\sigma_{x x}-\sigma_{y y}$ and $\sigma_{x x}-\sigma_{x y}$ stress planes when the temperature working is increased to $650^{\circ} \mathrm{C}$.

(3) Some specific UD laminate with imperfect interface bonding provides a higher resistant failure ability than all of the UD laminates with imperfect interface bonding in the $\sigma_{x x}-\sigma_{y y}$ stress plane and $\sigma_{x x}-\sigma_{x y}$ stress plane.

(4) For $[0 / \pm 45 / 90]_{s}$ composite laminates, the interfacial bonding modes can be ignored in the compressioncompression loading when the working temperature is increased to $650^{\circ} \mathrm{C}$.

\section{Conflict of Interests}

The authors declare that there is no conflict of interests regarding the publication of this paper.

\section{Acknowledgments}

This work was supported by the National Natural Science Foundation of China (nos. 51305320 and 51225501) and the Fundamental Research Funds for the Central Universities (K5051304003).

\section{References}

[1] M. Malathi, K. Tamilarasan, and V. Ganesan, "Role of ceramic reinforcement in composite polymer electrolyte," Polymer Composites, vol. 36, no. 1, pp. 42-46, 2015.

[2] V. P. Rajan, J. H. Shaw, M. N. Rossol, and F. W. Zok, "An elasticplastic constitutive model for ceramic composite laminates," Composites Part A: Applied Science and Manufacturing, vol. 66, pp. 44-57, 2014.

[3] H. R. Dana, F. Jacquemin, S. Fréour, A. Perronnet, P. Casari, and C. Lupi, "Numerical and experimental investigation of hygro mechanical states of glass fiber reinforced polyester composites experienced by FBG sensors," Composite Structures, vol. 116, pp. 38-47, 2014.

[4] E. Kiliçkap, A. Yardimeden, and Y. H. Çelik, "Investigation of experimental study of end milling of CFRP composite," Science and Engineering of Composite Materials, vol. 22, no. 1, pp. 89-95, 2015.

[5] R. K. Goldberg, "Utilization of the generalized method of cells to analyze the deformation response of laminated ceramic matrix composites," NASA/TM 2012-217737, 2012.

[6] J. Ye, X. Chen, Z. Zhai, B. Li, Y. Duan, and Z. He, "Predicting the elastoplastic response of fiber-reinforced metal matrix composites," Mechanics of Composite Materials, vol. 46, no. 4, pp. 405-416, 2010.
[7] M.-J. Pindera and B. A. Bednarcyk, "An efficient implementation of the generalized method of cells for unidirectional, multiphased composites with complex microstructures," Composites Part B: Engineering, vol. 30, no. 1, pp. 87-105, 1999.

[8] Z. W. Tang and B. M. Zhang, "Prediction of biaxial failure envelopes for composite laminates based on Generalized Method of Cells," Composites Part B: Engineering, vol. 43, no. 3, pp. 914-925, 2012.

[9] Z. Y. Sun, X. Y. Zhao, X. Wang, and J. S. Ma, "Predicting the elastic properties of sisal fiber reinforced polypropylene composites by a new method based on generalized method of cells and laminate analogy approach," Composites Science and Technology, vol. 91, pp. 45-49, 2014.

[10] J. Aboudi, "High-fidelity generalization method of cells for inelastic periodic multiphase materials," NASA Contractor Report TM-2002-211469, 2002.

[11] J. Aboudi and M. Ryvkin, "The effect of localized damage on the behavior of composites with periodic microstructure," International Journal of Engineering Science, vol. 52, pp. 41-55, 2012.

[12] R. Haj-Ali and J. Aboudi, "Formulation of the high-fidelity generalized method of cells with arbitrary cell geometry for refined micromechanics and damage in composites," International Journal of Solids and Structures, vol. 47, no. 25-26, pp. 3447-3461, 2010.

[13] E. Njuhovic, M. Bräu, F. Wolff-Fabris, K. Starzynski, and V. Altstädt, "Identification of interface failure mechanisms of metallized glass fibre reinforced composites using acoustic emission analysis," Composites B: Engineering, vol. 66, pp. 443452, 2014.

[14] E. Hervé-Luanco, "Elastic behavior of composites containing multi-layer coated particles with imperfect interface bonding conditions and application to size effects and mismatch in these composites," International Journal of Solids and Structures, vol. 51, no. 15-16, pp. 2865-2877, 2014.

[15] P. Soo-Jin, Interface Science and Composites, Elsevier, New York, NY, USA, 2011.

[16] B. A. Bednarcyk and S. M. Arnold, "Micromechanics-based deformation and failure prediction for longitudinally reinforced titanium composites," Composites Science and Technology, vol. 61, no. 5, pp. 705-729, 2001.

[17] S. M. Arnold, B. A. Bednarcyk, and J. Aboudi, "Comparison of the computational efficiency of the original versus reformulated high-fidelity generalized method of cells," NASA/TM 2004213438, 2004.

[18] X. F. Chen, J. J. Ye, Z. Zhai, and Z. J. He, "Micromechanical analysis of off-axis loading of fiber reinforced composites with imperfect interface bonding," International Journal of Mechanical Sciences, vol. 54, no. 1, pp. 113-120, 2012.

[19] B. A. Bednarcyk, S. M. Arnold, J. Aboudi, and M.-J. Pindera, "Local field effects in titanium matrix composites subject to fiber-matrix debonding," International Journal of Plasticity, vol. 20, no. 8-9, pp. 1707-1737, 2004.

[20] J. Aboudi, S. M. Arnold, and B. A. Bednarcyk, Micromechanics of Composite Materials-A Generalized Multiscale Analysis Approach, Elsevier, New York, NY, USA, 2013.

[21] J. J. Ye, X. F. Chen, Z. Zhai, B. Li, Y. Y. Zi, and Z. J. He, "Effects of thermal stress and imperfect interfacial bonding on the mechanical behavior of composites subjected to off-axis loading," Materials Science and Engineering A, vol. 527, no. 2930, pp. 7530-7537, 2010. 
[22] J. N. Reddy, Mechanics of Composite Materials, Springer, New York, NY, USA, 2010.

[23] S. M. Arnold and A. F. Saleeb, "On the thermodynamic framework of generalized coupled thermoelastic-viscoplasticdamage modeling," International Journal of Plasticity, vol. 10, no. 3, pp. 263-278, 1994.

[24] R. R. Cervay, "SCS-6/21s and SCS-9/21S mechanical property evaluation," Tech. Rep. NASP CR-1165, 1994. 

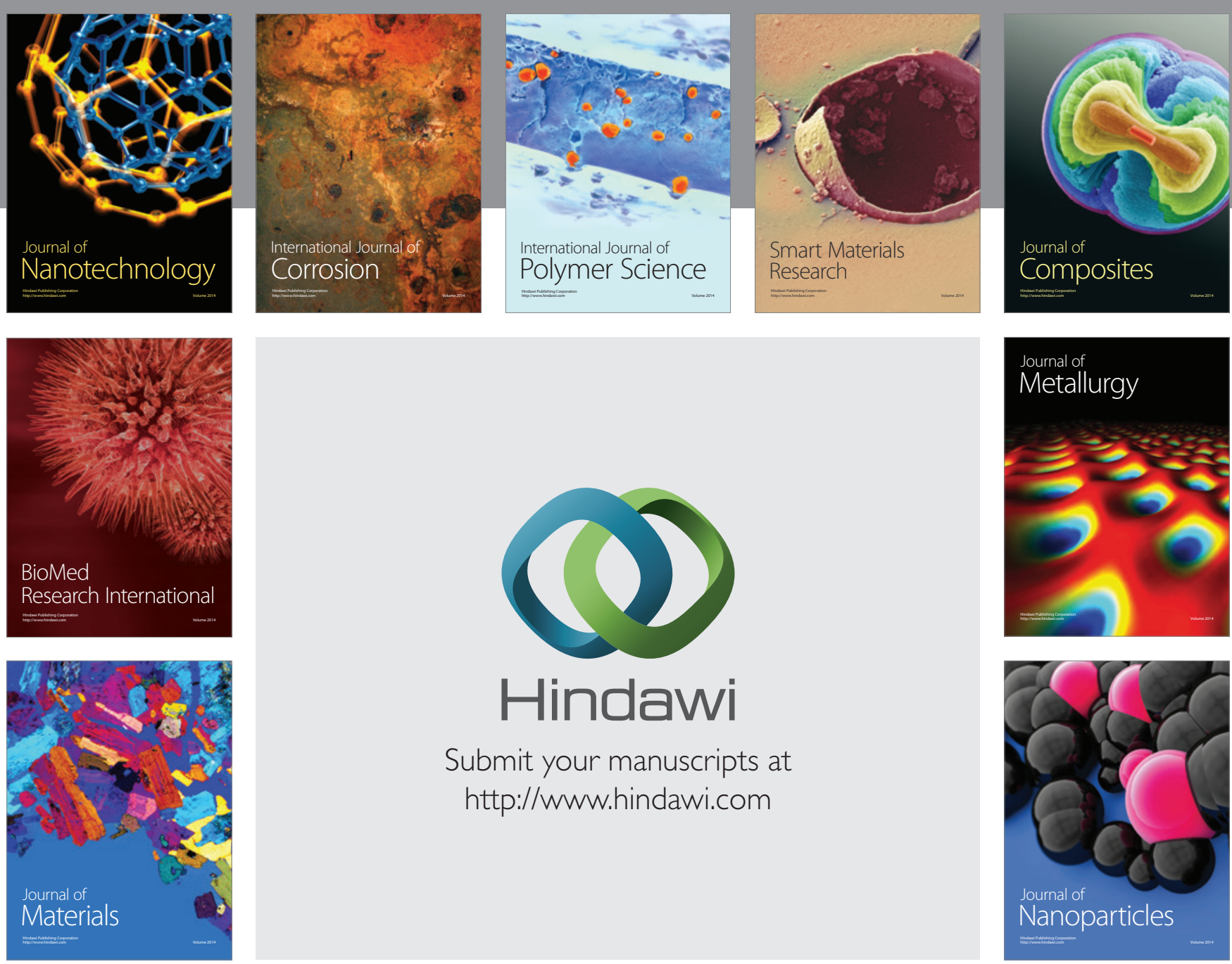

Submit your manuscripts at http://www.hindawi.com
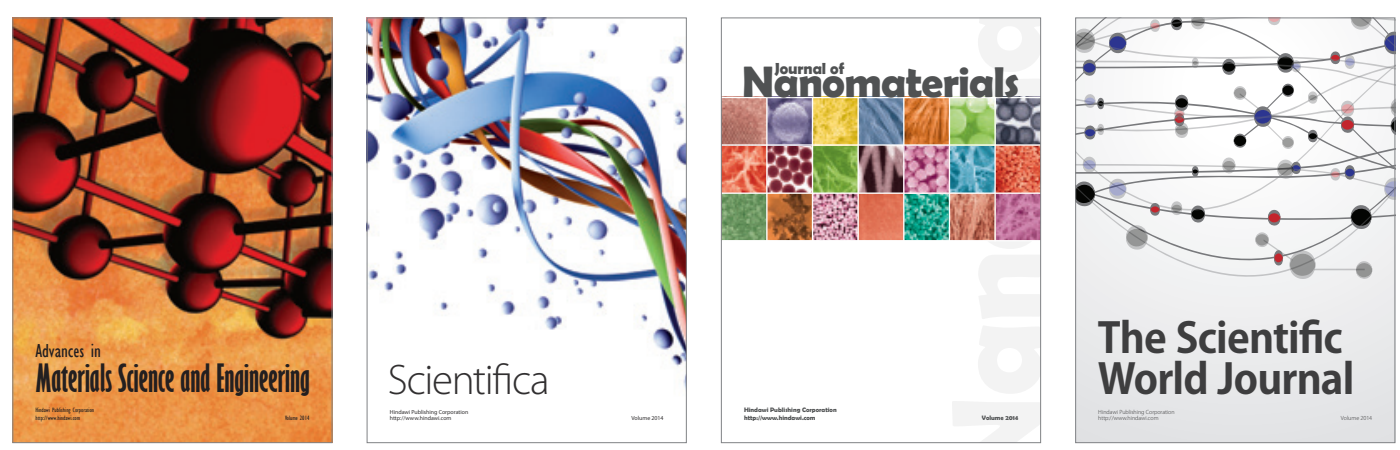

\section{The Scientific World Journal}
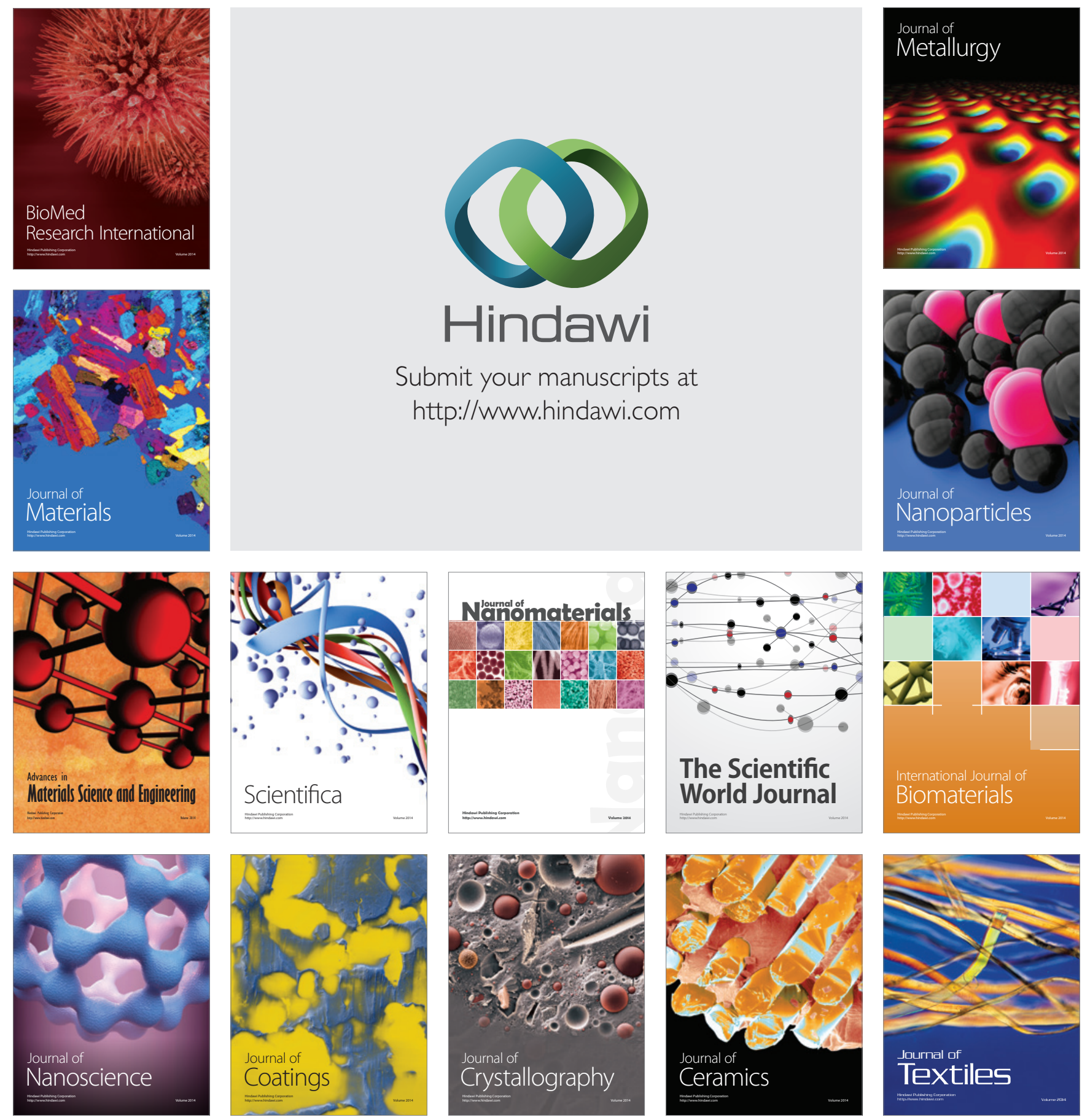